\title{
ENTRE O IDEAL E O REAL: A CONSTRUÇÃO DO PENSAMENTO EMPRESARIAL UBERLANDENSE E SEUS PROJETOS EDUCACIONAIS PARA A FORMAÇÃO DOS TRABALHADORES (1940-1960)
}

Luciene Maria de Souza

Carlos Alberto Lucena

Universidade Federal de Uberlândia - UFU

\section{RESUMO}

O propósito da pesquisa apresentada foi problematizar a construção do pensamento empresarial uberlandense representado pela Associação Comercial, Industrial e Agropecuária de Uberlândia e seus projetos educacionais para a formação dos trabalhadores. $\mathrm{O}$ estudo foi desenvolvido com uma ampla pesquisa bibliográfica e um levantamento minucioso de fontes documentais. Através da análise das atas da entidade e artigos de jornais locais foi possível problematizar os projetos políticos, econômicos, sociais e educacionais do empresariado para a cidade de Uberlândia. $\mathrm{O}$ acesso às fontes documentais nos permitiu resgatar a história econômica do município vinculando o cenário local com o desenvolvimento do capitalismo em nível nacional e internacional. Diferentemente do discurso oficial de cidade ideal, rica, industrializada, a pesquisa constatou a existência de outra realidade que foi ignorada por contrariar o projeto de cidade, idealizado pela elite econômica local. A Escola Vocacional e de Aprendizagem Industrial Américo Renê Giannetti foi selecionada como um dos principais projetos educacionais liderados pela Associação Comercial, Industrial e Agropecuária de Uberlândia. $\mathrm{O}$ intuito ao analisar a instituição escolar foi apreender a participação e os reais interesses da entidade junto aos poderes políticos locais e estaduais na criação da escola na cidade. Embora o desejo do empresariado fosse de transformar Uberlândia em Cidade Industrial como referência para toda a região mineira e para o país, a tese demonstrou que a cidade projetada idealizada foi diferente da cidade real.

Palavras-chave: Empresariado. Formação dos trabalhadores. Cidade Industrial.

\section{THE IDEAL AND THE REAL: UBERLANDIA'S BUSINESS THINKING DEVELOPMENT AND ITS EDUCATIONAL PROJECTS FOR WORKERS' TRAINING (1940-1960)}

\begin{abstract}
This work aims at presenting Uberlândia's business thinking development which is represented by the Chamber of Commerce, Industry and Agriculture of Uberlândia, and its educational projects for workers' training. The study was developed with an extensive literature search and a detailed survey of documentary sources. Through analysis of the entity's minutes and articles from local newspapers we could discuss the political, economic, social and educational projects of Uberlândia's entrepreneurs. Access to documentary sources allowed us to recover the city's economic history, linking the local scene to the development of capitalism in national and international level. Unlike the official discourse of the ideal, rich, and industrialized city, the thesis has found another reality that was ignored because it contradicts the city project, conceived by the local economic elite. The Vocational School of Industrial Learning Américo Renê Giannetti was selected as a major educational project led by the Chamber. Our objective in analyzing the school was to understand the participation and the real interests of the entity before the political local and state powers in creating the school in the city. Although the desire was
\end{abstract}


to transform Uberlândia into an Industrial City as a reference for the state and country, the thesis showed that the city was different from what was projected and idealized for it. Keywords: Entrepreneurship. Workers' training. Industrial City.

\section{Introdução}

O presente artigo é resultado de pesquisa de doutorado desenvolvida no Programa de Pós-Graduação em Educação da Universidade Federal de Uberlândia e teve como objetivo geral investigar a história econômica, política e social de Uberlândia bem como instaurar um debate sobre o projeto político pedagógico do empresariado uberlandense para a formação da classe trabalhadora na cidade. A pertinência do estudo está em recuperar o pensamento do empresariado uberlandense representado pela Associação Comercial, Industrial e Agropecuária de Uberlândia $^{1}$ (ACIAPU) articulado com os processos políticos, econômicos e socioculturais em âmbito nacional e internacional e suas mediações na elaboração de ações e propostas para a formação dos trabalhadores que resultou na criação da Escola Vocacional e de Aprendizagem Industrial Américo Renê Giannetti na cidade.

O recorte temporal delimitado para o desenvolvimento do estudo foi o período da década de 1940 a 1960, justificado pela ativa atuação da Associação Comercial, Industrial e Agropecuária de Uberlândia junto aos projetos de desenvolvimento econômico para a cidade que envolveu a luta por questões como: energia, água, transportes e ampliação do setor educacional.

A problematização desse processo implicou em perceber as mudanças em curso no capitalismo e seus impactos na sociedade. A década de 1920, período de efervescência intelectual, conflito político e crise econômica no Brasil, servirá como ponto de partida para esse estudo. O contexto socioeconômico da crise de 1929 afetou a economia brasileira até então baseada predominantemente no setor agrário-exportador apontando, gradativamente, para o investimento da burguesia nacional em processos de industrialização. Grande parte das mercadorias importadas foi produzida internamente, o que iniciou um processo conhecido por Substituição de Importações que foi fundamental para mover a economia do país. Em outros termos, ocorreu uma mudança no padrão de acumulação que passou a ser centrado na industrialização.

A partir desse período, estabeleceu-se uma nova relação entre Estado, burguesia nacional e economia no Brasil. Para Lucena (2004) é preciso considerar a transformação do papel do Estado diante do quadro de consolidação do capitalismo. A dinâmica do mercado mundial e a hegemonia da grande indústria foram subordinando e ajustando os Estados Nacionais aos interesses dinâmicos do capital internacional. O Estado Nacional tornou-se progressivamente essencial ao próprio desenvolvimento das forças produtivas, um aliado aos interesses da reprodução do capital, indispensável para a imposição de uma nova sociedade. Ao encampar as diretrizes propostas pela estratégia da industrialização o Estado fortaleceu a burguesia industrial como classe hegemônica defendendo, assim, seus projetos de modernização para o país. Uberlândia em sintonia com os desdobramentos econômicos em nível nacional e internacional empenhou-se em acompanhar, pelo menos em nível de discurso, o processo de industrialização que foi tomado como saída única para se retirar o Brasil da situação de atraso econômico em relação aos países desenvolvidos.

O projeto de interiorização da economia brasileira com a "marcha para Oeste", que iniciou durante o governo Vargas e prosseguiu com mais intensidade no governo Juscelino Kubitschek, propiciou a transferência da capital do Rio de Janeiro para Brasília, o que 
trouxe um crescimento econômico considerável para Uberlândia nas décadas de 50 e 60 do século XX. Em virtude de sua estratégica localização geográfica que liga os estados de grande relevância econômica e política do país, o município foi considerado um importante centro de abastecimento de força de trabalho e mercadorias para atender Brasília e regiões próximas. A construção de Brasília e a abertura de rodovias que interligaram Uberlândia à nova capital federal, impulsionaram um crescimento econômico como reflexo de um processo desenvolvimentista que estava em vigência no país.

Desse modo, entendemos que a construção do pensamento empresarial uberlandense é parte dos desdobramentos desse mesmo processo. O contexto de fundação da Associação Comercial, Industrial e Agropecuária de Uberlândia guarda relação com a crise do modelo agrário-exportador e o início da estruturação do modelo nacional desenvolvimentista baseado na industrialização e voltado para a expansão do capitalismo na economia brasileira. A pertinência do termo industrial no nome da entidade justificavase pelo desdobramento de um movimento de urbanização e modernização que o país vivenciava nesse período e o empresariado desejava que Uberlândia estivesse em sintonia com esse processo desenvolvimentista.

\section{A constituição histórica da ACIAPU e a construção do pensamento empresarial uberlandense.}

Dentre as entidades representantes do empresariado uberlandense selecionamos a Associação Comercial, Industrial e Agropecuária de Uberlândia (ACIAPU) por considerála a entidade patronal mais atuante e influente na "vida" política, econômica e educacional da cidade. Optou-se pelo estudo do empresariado pela ótica da Associação buscando investigar sua atuação, sua visão de mundo e sociedade e seu projeto de formação humana para a classe trabalhadora na cidade, além de seu olhar quanto às relações sociais e ao processo de industrialização.

A criação da ACIAPU na década de 1930 não ocorreu no vazio, mas se explicou pelo movimento de crise internacional do capitalismo nas primeiras décadas do século XX. A crise de superprodução gestada pelo capital pós 1929 implicou na necessidade de uma reestruturação do mundo produtivo para manutenção da sobrevivência dos países dentro desse modelo de economia. Com o Brasil não foi diferente. Os reflexos desse fenômeno incentivaram a produção interna de mercadorias levando ao chamado processo de Substituição de Importações, responsável pela mudança lenta e gradual de uma economia agrário-exportadora para uma urbano-industrial. Todo esse cenário provocou um intenso processo de urbanização que impactou na formação de uma nova classe trabalhadora bem como na organização de um novo empresariado que precisava se fortalecer politicamente para fazer frente de seus interesses junto ao Estado nacional.

Foi nesse contexto que foram formadas as primeiras entidades patronais, a exemplo da Associação Comercial, Industrial e Agropecuária de Uberlândia. A Associação se constituiu com o intuito de congregar os interesses do empresariado ligado aos setores agropecuário, comercial e industrial. Segundo o discurso empresarial a cidade necessitava se consolidar como referência de desenvolvimento econômico na região e para isso deveria oferecer condições básicas de infraestrutura a fim de atrair o capital nacional e internacional e receber novos investimentos.

Em determinados momentos, tamanha era a luta desta entidade no tocante à construção da infraestrutura necessária ao atendimento dos interesses das classes produtivas, das quais era a legítima representante, que, ao lermos distraidamente suas atas, poderíamos nos enganar pensando ser 
uma entidade de caráter técnico na área de construção de estradas; ou de serviços de telecomunicações; ou um órgão municipal responsável pelo abastecimento de água; ou um corpo técnico de assessoria a uma empresa fornecedora de energia elétrica. Podemos dizer que várias foram as articulações empreendidas por todas as diretorias dessa entidade na defesa dos interesses de seus associados que, no seu conjunto, representavam o interesse de uma cidade dotada de visão de futuro e consciente da força para trilhar elevados caminhos. (ACIUB, 1998, p. 9 , grifo nosso).

As atribuições da Associação em relação à defesa dos interesses dos setores produtores do comércio, indústria, agricultura e pecuária foram enfatizadas na Assembleia Geral que ocorreu em 1957 na sede da entidade.

Pugnar pela defesa dos interesses das classes que representa, tornando-se seu legítimo órgão; manter-lhes sempre elevado o nível moral e intelectual; desenvolver entre os comerciantes, industriais e agricultores e criadores, o espírito de solidariedade e cooperação; Promover a representação do comércio, da indústria, da agricultura e da pecuária nas Assembleias Legislativas do Município, do Estado e da Federação; desempenhar todas as funções que o código do comércio e demais leis do país conferem às Associações Comerciais; Contribuir para que os usos da praça se baseiem sempre na equidade, evitando desavenças entre associados do mesmo ramo de negócios; Amparar com o seu prestígio o sócio envolvido em questões injustas, provocadas ou não por ele. (ACIAPU, 12 dez. 1957, p. 88, grifo nosso).

Sem dúvida, a união de forças entre os diferentes setores do empresariado foi muito importante para o fortalecimento da entidade no sentido de reivindicar seus interesses junto ao Estado e aos poderes públicos locais. A própria denominação Associação Comercial, Industrial e Agropecuária de Uberlândia indicou pelo menos no campo da aparência uma congregação entre os diferentes setores econômicos: agricultores, pecuaristas, industriais e comerciantes. Sempre que possível reforçavam a união dos seus diferentes setores representados.

A união faz a força? O exemplo da Associação Comercial, Industrial e Agropecuária de Uberlândia nos responde que sim. Durante a década de 30, ocorreu, no Brasil, um movimento em torno da organização da sociedade, tanto por parte das classes trabalhadoras como também por parte dos empresários. Em Uberlândia, a formação de uma associação que congregava comerciantes, industriais, agricultores e criadores, estendida a todos aqueles que podiam lhe prestar serviços, acompanhava esse movimento nacional. (ACIUB, 1998, p. 16).

Entretanto, consideramos importante refletirmos até que ponto realmente foi possível a união entre esses diferentes setores empresariais, conforme apontado no discurso acima. Oliveira (2002), ao interrogar quem foram os sujeitos que compunham o empresariado uberlandense e se existiu de fato conflito entre os setores urbano e rural, afirmou que a palavra de ordem da burguesia local foi união, e a principal instituição que representava seus interesses, a ACIAPU, foi durante muito tempo representante também dos setores rurais. "Essas três classes produtoras (comércio, indústria e setor agropecuário), como sempre aconteceu em Uberlândia, trabalhavam sob a égide de sua entidade, coesas e 
com tenacidade, em prol do desenvolvimento da nossa comunidade". (OLIVEIRA, 2002, p.20).

Para tanto, discordamos do posicionamento adotado pelo autor por considerarmos passíveis de questionamento as teses que defendem a não existência de conflitos de interesses entre os setores vinculados ao comércio, indústria e agropecuária. As atribuições da Associação apresentadas no Estatuto da entidade manifestavam uma evidente preocupação da diretoria em enfatizar a solidariedade e cooperação entre os associados. Para tanto, esse desafio não foi enfrentado somente pela ACIAPU. Conforme aponta Pereira e Faria (2001) a Associação Comercial de Minas em Belo Horizonte representante do empresariado mineiro enfrentava a mesma situação. Era necessário neutralizar discursos dissidentes para que o empresariado pudesse apresentar-se como um grupo articulado entre os diversos setores econômicos.

A reunião ocorrida no ano de 1969 na Associação foi um dos exemplos das manifestações dos conflitos de interesses existentes entre os setores do empresariado uberlandense vinculados ao comércio, indústria e agropecuária. A diretoria da ACIAPU no dia 15 de abril de 1969 convocou os associados para participarem de uma Assembleia Geral Extraordinária que teve como pauta a mudança do nome da entidade e a sugestão de criação de uma Fundação do Centro das Indústrias de Uberlândia. A proposta da diretoria era que se retirasse do nome da Associação a designação de agropecuária tendo em vista "a cessação das atividades da entidade nesse setor da produção desde que aqui se fundou a Associação Rural”. (ACIAPU, 15 abr. 1969, p. 189). Após discussão e votação, a proposta de mudança do nome da entidade foi aprovada por unanimidade entre os associados, ficando definida a nomenclatura de Associação Comercial e Industrial de Uberlândia (ACIUB).

Em relação à criação do Centro das Indústrias de Uberlândia, a diretoria propunha sua imediata fundação. Para tanto, a ideia não foi aceita por todos os associados. Alguns membros da entidade questionaram a inconveniência da proposta, alegando que isto poderia trazer para a cidade a separação das atividades sociais do comércio e da indústria provocando "um enfraquecimento de duas forças que, nesta conjuntura, unidas se vêm mostrando laboriosas e atuantes". (ACIAPU, 15 abr. 1969, p. 190). Assim, a criação do Centro das Indústrias encontrou resistência, tornando inviável sua execução.

Diante disso, cabem alguns questionamentos. Se os setores empresariais eram unidos, conforme apontava o discurso, porque então o desejo em se dividirem em Associações distintas? Por que se criar um Centro das Indústrias com o intuito de se substituir a própria Associação? Os debates presentes nos documentos demonstraram os conflitos políticos e jogo de forças presentes entre esses setores empresariais. Embora no campo da aparência o discurso seja o da homogeneidade, coesão e união dos diferentes setores, o que se percebe na materialidade é exatamente o oposto. A busca pela convergência de interesses entre os diferentes grupos empresariais era um desafio ainda distante de ser conquistado pela Associação Comercial, Industrial e Agropecuária de Uberlândia.

Diante disso, podemos afirmar que os projetos do empresariado ligado à ACIAPU não foram coesos e articulados como apresentados por seus integrantes. Constatamos, ao analisar os documentos da entidade, a presença de fissuras em seu interior que se expressavam pelos diferentes interesses das frações de classe que a compunha. $O$ empresariado ligado aos setores comercial, industrial e agrícola nem sempre compartilhavam os mesmos projetos. O que ocorreu constantemente foi um jogo de forças em que ora sobressaía o interesse de um grupo ora de outro. Esse fato demonstra como o empresariado é, em muitas situações, desarticulado em seus projetos, por mais que no 
campo da aparência se preocupasse em transmitir a impressão de unido e integrado; na prática as divergências são notórias.

A ACIAPU, em sintonia com o ideário nacional desenvolvimentista, liderou vários projetos. Dentre eles o que obteve grande ênfase foi o sonho de transformar Uberlândia em Cidade Industrial com referência não somente na região, mas no país. A ACIAPU implementou uma campanha pró-industrialização na cidade procurando envolver toda a comunidade nesse projeto, além de convidar grandes empresas a instalaram aqui unidades fabris. Empresas multinacionais e nacionais, de economia mista, privada ou estatal, de qualquer ramo industrial, sofriam os assédios da entidade. Argumentava-se que Uberlândia tinha necessidade imediata de industrializar-se, "pois outros centros que dependiam desta em passado recente, já estão hoje se tornando autônomos, por já disporem de facilidade de crédito, pelo avanço da rede bancária, de energia elétrica e de meios de transportes, através do incremento dos caminhões e da construção de rodovias". (ACIAPU, 25 nov. 1958, p. 117).

Para tanto, constatamos através da pesquisa realizada que foi apenas desejo, pois até o final da década de 1960 a cidade, assim como grande parte dos municípios que compõem o estado de Minas Gerais, enfrentava sérios problemas de racionamento de água, energia e transportes. A Associação esforçou-se em divulgar as potencialidades econômicas do município a fim de atrair novos investimentos, mas não foi suficiente para mudar os rumos da economia da cidade. Por mais que o discurso tentasse apresentar a cidade como progressista e moderna, Uberlândia não conseguiu pelo menos até o final do período analisado perder seu perfil de cidade agropecuária. Até mesmo as poucas indústrias instaladas estavam ligadas ao setor agroindustrial. Economicamente, além do setor agropecuário a cidade destacou-se, sobretudo com a construção de Brasília, no comércio varejista e principalmente no ramo atacadista.

No que se refere aos projetos educativos defendidos pela ACIAPU, a Escola Vocacional e de Aprendizagem Industrial Américo Renê Giannetti foi selecionada como um dos principais projetos educacionais liderados pela Associação. O intuito ao analisar a instituição escolar foi apreender a participação e os reais interesses da entidade junto aos poderes políticos locais e estaduais na criação da escola na cidade. A Associação desejou a criação da Escola Vocacional a fim de contribuir para o projeto de sociedade e educação que pensava para a cidade. A preocupação em formar a força de trabalho uberlandense a fim de atender as necessidades de desenvolvimento econômico do município e região foi tema recorrente nas reuniões do empresariado local na Associação. Além da preocupação de interferir na relação educação e mundo do trabalho com o intuito de adestrar tecnicamente a força de trabalho para atender as novas indústrias que chegavam à cidade também existia uma preocupação da Associação em formar esses trabalhadores no aspecto moral para além dos muros das fábricas.

\section{A ACIAPU e seus projetos educacionais para a formação dos trabalhadores.}

A partir de leituras de dissertações e teses sobre a educação profissionalizante em Uberlândia bem como análise dos documentos pesquisados no período em apreço identificamos uma constância de debates e discursos em torno da criação da Escola Vocacional e de Aprendizagem Industrial Américo Renê Giannetti. Diante disso, nosso objetivo foi identificar como ocorreu a participação e influência da ACIAPU nesse processo. Foram quase duas décadas ${ }^{2}$ de idealização e solicitação do empresariado junto aos representantes da política local, estadual e federal para a instalação da Escola Vocacional na cidade. 
O empresariado uberlandense representado pela Associação Comercial, Industrial e Agropecuária de Uberlândia desde os anos 1940 preocupou-se em propor projetos de formação dos trabalhadores a fim de atender às novas necessidades socioeconômicas que se despontava no período. O desejo para que Uberlândia entrasse em sintonia com o desenvolvimento industrial que se fortalecia no país, principalmente no estado de São Paulo, impulsionou o empresariado local a articular a criação de uma Escola Vocacional industrial para a cidade. O discurso da entidade demonstrava sua influência direta na criação de inúmeras instituições escolares na cidade ao afirmarem que a Associação,

Esteve à frente na criação de uma escola técnica industrial, Escola Estadual Américo Renê Giannetti, e de outros cursos técnicos fornecidos pelo SESC, SESI e SENAI. Fornecia bolsas de estudos. Também empenhou-se ao lado do mestre Eugênio Arantes Pimentel na luta pela instalação da Escola Agrotécnica. E não foram de menor monta os empenhos para a criação das faculdades, depois a Universidade e, por fim, pela federalização da atual Universidade Federal de Uberlândia. E com todas essas instituições de ensino, a ACIUB continua fazendo belas e proveitosas parcerias. (ACIUB, 1998, p. 15).

Em virtude da predominância agrária da economia do estado de Minas Gerais, a criação de escolas vocacionais industriais até início do século XX não foi prioridade das políticas públicas educacionais no estado. Contudo diante da nova configuração do capitalismo no Brasil, uma das metas assumidas no Plano de Recuperação Econômica e Fomento da Produção do Estado de Minas Gerais em 1947 pelo Governador Milton Soares Campos foi o projeto de criar Escolas Vocacionais agrícolas e industriais a fim de atender a formação técnica necessária ao fortalecimento da economia do estado. Mundim (2005) destaca que a proposta da ACIAPU contou com o apoio dos poderes executivo e legislativo municipal. Em visita do Secretário da Agricultura, Indústria, Comércio e Trabalho de Minas Gerais em Uberlândia, o presidente da ACIAPU teve a oportunidade de conversar a respeito das necessidades educacionais do município sugerindo a criação de uma escola vocacional que foi sinalizada positivamente pelas autoridades político-estaduais.

O processo de industrialização vivenciado no país despertou a necessidade de formação especializada da força de trabalho e as escolas de ensino técnicoprofissionalizante passaram a ser prioridade na perspectiva das políticas públicas educacionais. O presidente Juscelino Kubitschek nas mensagens presidenciais dirigidas ao Congresso Nacional expressou essa mesma preocupação ao ressaltar a necessidade de formação de técnicos para atender a expansão das indústrias e da agricultura. Diante da importância que tais questões exerciam no cenário de desenvolvimento econômico nacional, a educação técnica profissionalizante em seu governo passaria a ser um problema de infraestrutura. (BRASIL, 1978).

A Associação em consonância com esse processo desejou profundamente a criação da Escola Vocacional a fim de contribuir para o projeto de sociedade e educação que pensava para a cidade. Envolvidos no discurso nacionalista idortiano ${ }^{3}$ fundamentado nos princípios tayloristas de organização científica do trabalho e norteados pelas concepções de tempo útil, racionalidade e lucro de que o "mundo é da técnica e dos técnicos", acreditavam que a escola vocacional deveria cumprir seu papel de formação técnica e moral para o trabalho.

Ao procurar incutir o valor do trabalho e de disciplina às pessoas que estavam marginalizadas na cidade, a Escola Vocacional atendia o projeto de cidade defendido pelos setores empresariais. O empresariado ligado à ACIAPU apostava que com a oferta dos 
cursos profissionalizantes era possível reduzir os problemas de marginalidade social e preservar a imagem de Cidade-Jardim ${ }^{4}$, limpa e ordeira, importante para a vinda de empresas e investimentos econômicos no município. A imagem de cidade tranquila e esteticamente atraente foi uma meta perseguida pelo empresariado e autoridades políticas locais. Esse discurso calcado nos parâmetros de ordem, progresso, estética e higiene tiveram o intuito de viabilizar o desenvolvimento da cidade e a sua expansão econômica, bem como tentar manter sob controle e dominação a formação da classe trabalhadora.

O cuidado para preservar a imagem de "Cidade Jardim" e a preocupação em camuflar todo tipo de conflito social entre capital e trabalho foi uma das estratégias adotadas pelos setores empresariais uberlandense para reforçar a ideologia de cidade ordeira e progressista. O sedutor discurso do empresariado apresentava a cidade como se esta estivesse predestinada ao progresso. Para tanto, contraditoriamente a essa concepção conservadora e ideológica, pesquisas ${ }^{5}$ sobre a história sócio-econômica e política de Uberlândia demonstraram que a população não foi tão ordeira e disciplinada como o discurso apresentava. Alguns acontecimentos ocorridos na cidade como a organização ${ }^{6}$ política dos trabalhadores em entidades, associações e sindicatos; o movimento de contestação popular denominado Quebra-Quebra em 1959 e a articulada presença dos comunistas em Uberlândia foram exemplos de que o projeto dominante não foi compartilhado de forma pacífica por todo o "povo uberlandense".

De uma forma geral, entre as reivindicações da classe trabalhadora destacava-se a luta pelo aumento salarial e o cumprimento da legislação trabalhista que era ignorada por muitos empresários na cidade.

As denúncias contra o alto custo de vida, a luta pelo cumprimento da legislação trabalhista, as campanhas salariais, as comissões de tabelamento e reivindicações para a plena assistência médica foram uma constante. Essas eram as reivindicações básicas da classe trabalhadora uberlandense, expressas nas suas inúmeras manifestações. Foram as condições elementares para fazê-la se expressar na luta por condições dignas de trabalho e sobrevivência. (RODRIGUES, 1989, p. 96).

Por mais que o discurso ideológico insistisse em afirmar a eterna parceria entre capital e trabalho, a realidade histórica demonstrou que Uberlândia vivenciou nas décadas de 1940 a 1960 muitos conflitos de classes. Os trabalhadores não aceitaram as condições de precariedade impostas e para lutar por seus direitos se uniram em entidades representativas como o Círculo Operário, o Sindicato dos trabalhadores nas Indústrias de Alimentação de Uberlândia e a Associação Profissional dos Condutores de Veículos Rodoviários de Uberlândia também denominada de Associação dos Motoristas.

O discurso conservador local apresentou Uberlândia como cidade ideal, rica, próspera, uma "verdadeira capital no interior do Brasil" em conflito com uma cidade real que apresentava altos índices de violência, mendicância e conflitos ${ }^{7}$. O movimento denominado Quebra-Quebra em Uberlândia ocorrido nos dias 18 e 19 de janeiro de 1959 ilustra esse cenário. O Quebra-Quebra foi uma contestação popular que expressou a insatisfação da classe trabalhadora com os baixos níveis salariais e os altos índices de inflação $^{8}$ vivenciados no Brasil nesse período, demonstrando que a população uberlandense não pactuou plenamente com os projetos apresentados pelo ideário burguês.

$\mathrm{O}$ fato é que o país enfrentava um período inflacionário na economia que afetava, sobretudo, a classe trabalhadora com o encarecimento do custo de vida e que por consequência refletia no processo de acumulação e reprodução do capital. Para Cardoso (2003) a inflação foi encarada como um problema que estrangulava o desenvolvimento 
econômico. Segundo a imprensa local a situação nacional era aflitiva sendo o governo culpado pelo difícil momento enfrentado pela economia brasileira.

\begin{abstract}
Não somos os únicos e nem os primeiros a contemplar e considerar a contraditória situação econômico-financeira nacional e as suas sombrias perspectivas. Nem precisa ser autoridade na questão para enxergá-la nos seus devidos termos. (...) a inflação galopante, provinda das continuadas e elevadas emissões de papel moeda, não parou, como não pararam seus reflexos no custo de vida, no estrangulamento dos orçamentos públicos e na desvalorização do dinheiro. A posição cambial do país permanece aflitiva, quer no sentido da exportação quer na importação. (CORREIO DE UBERLÂNDIA, 18 dez. 1958, p. 01).
\end{abstract}

O cenário econômico nacional favoreceu a contestação popular, mas o estopim para desencadear o início das manifestações locais segundo Almeida (1992) foi o abusivo aumento no preço do ingresso do cinema que girou na casa de $70 \%$. Os estudantes em sua maioria que estavam na fila do cinema ficaram indignados com a alta dos preços do ingresso e movimentaram uma parcela da população trabalhadora, que já não estava satisfeita com o aumento do custo de vida, a se rebelar, o que resultou na depredação dos cinemas locais e saques de mercadorias em casas comerciais de grande porte na cidade. Foram dois dias de manifestações que resultaram na morte de duas pessoas e prisão de duzentos suspeitos envolvidos com os protestos.

A Associação Comercial, Industrial e Agropecuária de Uberlândia foi convidada pela imprensa uberlandense a se manifestar a respeito do episódio acontecido. A declaração de um dos membros da diretoria da Associação ressaltou que violência, agitação e a discórdia não constroem e ainda pronunciou que,

Com desolação e com pesar refletiram em nosso ânimo os reprováveis acontecimentos. Uberlândia e seu povo não merecia uma tão infeliz propaganda. Os responsáveis pelos fatos, porque responsáveis devem existir, deram prova de desprezo e de falta de amor a esta cidade acolhedora e pródiga. Outra é a civilização do uberlandense, tão afeito ao trabalho, ao progresso, ao respeito para com o próximo. Isso tudo, largamente divulgado e comentado em todo o país, mais ainda nos entristeceu. De outro lado, homens dedicados ao progresso da cidade, identificados com o nosso meio e com os nossos costumes, receberam injustificável agressão, que de resto, cumpria ao poder público evitar. Esta página negra deve ser virada em definitivo. (CORREIO DE UBERLÂNDIA, 15 fev. 1959, p. 01).

O sistema repressivo montado após os dias de protestos expressou a vontade dos setores empresariais de abafar e punir os culpados pelo encabeçamento da manifestação para servir de exemplo aos demais. A ACIAPU, após a onda de protestos e saques, exigiu a instalação de uma unidade do exército na cidade bem como também a instalação de uma Penitenciária regional. O Quebra-Quebra trouxe a Uberlândia o $4^{\circ}$ Batalhão de Infantaria de Uberaba e ainda policiais de Araguari e Tupaciguara para reforçar a segurança local. "Chegaram reforços também de Belo Horizonte e vieram até integrantes da aeronáutica paulista. A polícia federal se fez presente para identificar e caçar comunistas. Caçada muito apreciada à época". (VASCONCELLOS, 1993, p. 56).

Diante da amplitude dos protestos ocorridos em Uberlândia com o Quebra de 1959, a preocupação dos discursos da imprensa, do empresariado, dos políticos e do poder 
público municipal foi desvirtuar a dimensão política da manifestação popular para outras instâncias. Longe de ser tomado como um movimento popular de resistência às precárias condições de vida dos trabalhadores, este foi entendido pelos setores econômicos uberlandense como expressão de baderneiros e marginais que aproveitaram da rebeldia dos estudantes para saquear, depredar e manchar a imagem da "Cidade Jardim" em que reinava a disciplina, ordem e progresso. Acreditamos que o posicionamento adotado esteja relacionado com o receio da imprensa de dar a devida importância à manifestação popular $\mathrm{e}$, consequentemente, manchar a imagem de cidade ordeira e tranquila que se tinha forjado diante da mídia nacional. O não manifestar-se traz em si também a percepção que os setores empresariais tinham a respeito desses protestos. O Quebra-Quebra na visão do empresariado foi uma manifestação para ser apagada da memória da cidade, um fato inusitado e não correspondia com a índole pacífica do povo uberlandense. Na verdade os setores empresariais uberlandenses estavam preocupados com os reflexos dessa manifestação no contexto nacional no que concerne à vinda de empresas e investimentos econômicos para o município.

Essas manifestações e tensões sociais nos permitem concluir que as formas de dominação dos setores empresariais sobre a classe trabalhadora não ocorreu de forma harmoniosa como discorreram os discursos oficiais presentes nas atas da ACIAPU e periódicos da cidade, mas ocorreu de forma conflituosa. Diversos instrumentos e ideologias foram utilizados para tentar manter essa relação sob controle, mas parte da população não se identificou com o projeto burguês uberlandense de ordem e progresso. A imagem de cidade ideal, modelo para toda a região mineira e para o país, foi refutada por parte da população.

\section{Considerações Finais}

A pertinência da pesquisa está em identificar como os setores empresariais representados pela Associação Comercial, Industrial e Agropecuária enfrentou os conflitos advindos da sociedade e do Estado e esteve profundamente em sintonia com as alterações do capitalismo mundial sendo capaz de conceber e sustentar seu próprio projeto político pedagógico de homem, sociedade e mundo. Desse modo, tendo como referência a problematização do que as fontes apresentam e o que as bibliografias dão de sustentação, ultrapassamos o discurso ideológico dos setores empresariais uberlandenses emitidos pelos documentos oficiais, elaborando um estudo que objetivou ir além da aparência buscando apreender a essência do pensamento empresarial e seus projetos educativos complexos e contraditórios expressos na totalidade do seu tempo.

Portanto, com o objetivo de fazer um contraponto ao pensamento do empresariado ligado à ACIAPU, defendemos a tese de que, apesar da existência de um discurso conservador, manifesto na defesa de uma cidade ideal, progressista e industrializada, alicerçada no discurso ideológico da parceria entre capital e trabalho, a história manifesta em sua materialidade e movimento tratou de desmentir esses pressupostos econômicos e políticos. Por mais que o empresariado ligado à ACIAPU tivesse projetado desde os anos 1940 que Uberlândia se tornaria um poderoso centro industrial, na verdade foram sonhos, projetos, idealizações que a história se encarregou de demonstrar que tais projetos não se materializaram na realidade da forma como foram pensados. De fato, a cidade historicamente se destacou por sua preponderância agropecuária e comercial, sobretudo no ramo atacadista. $\mathrm{O}$ desejo de transformar Uberlândia numa Cidade Industrial, o projeto de transformar a Escola Vocacional e de Aprendizagem Industrial Américo Renê Giannetti em um influente Centro Regional de formação técnico-profissionalizante não se 
concretizaram, pelo menos não da forma como foi idealizado em suas propostas iniciais. Desconstruir o discurso ideológico do empresariado uberlandense ligado à ACIAPU que foi tecido de forma tão bem articulada a princípio pode parecer uma "heresia" à memória desses homens que foram denominados por alguns memorialistas locais como "visionários", "empreendedores" e "protagonistas" do desenvolvimento econômico de Uberlândia. Para tanto, o desafio deste estudo foi demonstrar que a construção da história do município não foi tecida de forma linear como descreveu o pensamento empresarial, mas foi repleta de contradições, conflitos e confrontos inerentes à relação capital e trabalho presente no modo capitalista de produção.

Para tanto, a pesquisa apresentada não teve a intenção de esgotar a temática, que, diga-se de passagem, tem sido muito pouco estudada no meio acadêmico, mas o desejo é que a partir das considerações elaboradas possa incentivar outros pesquisadores a dar continuidade aos estudos sobre o pensamento empresarial brasileiro e mais especificamente o uberlandense que se apresenta como um campo fértil para se investigar como se articulam, se fortalecem e se fragmentam os projetos da elite. A proposta foi apreender como os discursos das classes dominantes são tecidos, como as ideologias são construídas para assim permitir a possibilidade de construção de outra leitura a respeito da história socioeconômica, política e educacional de Uberlândia. Com bem salienta Trevisan (1986) não só é possível como necessário reescrevermos outra história, diferente do discurso oficial e que privilegie a luta de classes enquanto lócus por excelência da história e, nesse sentido, definidora também de qual história será escrita e por quem.

\section{Referências}

A violência, a agitação e a discórdia não constroem. Correio de Uberlândia, Uberlândia, 15 fev. 1959, p. 01.

ACIAPU. Ata $n^{0} 1.431$ da reunião extraordinária para mudança de nome da entidade e fundação do Centro Industrial de Uberlândia realizada no dia 15 abr. 1969. Uberlândia, 1969. Livro 20, p. 189.

ACIAPU. Ata no 947 da reunião realizada no dia 25 nov. 1958. Uberlândia, 1958. Livro 16, p. 117.

ACIAPU. Ata no 907 da reunião realizada no dia 12 dez. 1957. Uberlândia, 1957. Livro 15, p. 88.

ACIUB. Portfólio 65 anos. In: ACIUB em Revista. Edição Extra. Uberlândia: Gráfica Sabe, 1998.

ALMEIDA, M. F. R. Uberlândia operária? Uma abordagem sobre as relações sociais em Uberlândia (1950 - 1964). 1992. 149f. Dissertação (Mestrado em História) - Instituto de Filosofia e Ciências Humanas da Universidade Estadual de Campinas, São Paulo, 1992.

BRASIL. Mensagens presidenciais (1945 - 1964): Eurico Gaspar Dutra, Getúlio Vargas, Café Filho, Juscelino Kubitschek de Oliveira, Jânio da Silva Quadros, João Goulart. Brasília: Câmara dos Deputados, 1978. 
CARDOSO, Heloisa Helena P. O ideário do empresariado mineiro nos anos 50: liberdade econômica, propriedade privada e justiça social. In: MACHADO, Maria Clara T.; PATRIOTA, Rosangela (Orgs). Histórias e Historiografia: perspectivas contemporâneas de investigação. Uberlândia, MG: EDUFU, 2003.

CUNHA, Luiz A. O ensino profissional na irradiação do industrialismo. São Paulo: Editora UNESP, Brasília, DF: FLACSO, 2000.

GUIMARÃES, Eduardo N. Formação e Desenvolvimento Econômico do Triângulo Mineiro: integração nacional e consolidação regional. Uberlândia: EDUFU, 2010.

LUCENA, Carlos. Tempos de Destruição: Educação, Trabalho e Indústria do Petróleo no Brasil. Campinas, SP: Autores Associados. Uberlândia, MG: EDUFU, 2004.

MUNDIM, Maria O. P. O Ensino Vocacional no Brasil: a experiência da Escola de Aprendizagem Industrial Américo Renê Giannetti (Uberlândia 1962 - 1983). 2005. $173 f$. Dissertação (Mestrado em Educação) - Faculdade de Educação da Universidade Federal de Uberlândia, Uberlândia, 2005.

OLIVEIRA, Selmane F. Crescimento urbano e ideologia burguesa: estudo do desenvolvimento capitalista em cidades de médio porte: Uberlândia (1950 - 1985). Uberlândia: Rápida Editora, 2002.

PEREIRA, Lígia M. L.; FARIA, Maria A. de. Associação Comercial de Minas: uma história de pioneirismo e desenvolvimento 1901 - 2001. Belo Horizonte: Associação Comercial de Minas, 2001.

RODRIGUES, Jane de Fátima S. Trabalho, ordem e progresso: uma discussão sobre a trajetória da classe trabalhadora uberlandense - o setor de serviços (1924 - 1964). 1989. 214f. Dissertação (Mestrado em História). Faculdade de Filosofia, Letras e Ciências Humanas da Universidade de São Paulo, São Paulo, 1989.

SILVA, Idalice R. "Flores do Mal" na Cidade Jardim: comunismo e anticomunismo em Uberlândia. 1945 - 1954. 2000. 444f. Dissertação (Mestrado em História) - Instituto de Filosofia e Ciências Humanas da Universidade Estadual de Campinas, São Paulo, 2000.

SITUAÇÃO nacional é aflitiva: governo culpado. Correio de Uberlândia, Uberlândia, 18 dez. 1958, p. 01.

SOARES, B. R. Uberlândia: da Cidade Jardim ao Portal do Cerrado. Imagens e representações no Triângulo Mineiro. 1995. Tese (Doutorado em Geografia) Universidade de São Paulo, São Paulo, 1995.

SOUZA JÚNIOR, Geraldo Veiga de. Polícia/Crime. In: MACHADO, Maria Clara T.; LOPES, Valéria M. Q. C. (Orgs). Caminho das pedras: inventário temático de fontes documentais. Uberlândia - 1900/1980. Uberlândia, MG: EDUFU, 2007.

TREVISAN, Maria José. 50 anos em 5... A FIESP e o Desenvolvimentismo. Rio de Janeiro: Vozes, 1986. 
VASCONCELlOS, Maria H. F. Dias de violência - o Quebra de janeiro de 59 em Uberlândia. 1993. 108f. Dissertação (Mestrado em Educação) - Faculdade de Educação, Universidade Estadual de Campinas, 1993.

\section{Notas:}

${ }^{1}$ A entidade no período de 1933 até 1969 intitulou-se Associação Comercial, Industrial e Agropecuária de Uberlândia (ACIAPU). Após esse período foi retirado o termo agropecuário de sua razão social passando então a denominar-se Associação Comercial e Industrial de Uberlândia (ACIUB).

${ }^{2}$ Embora o Decreto de criação da Escola Vocacional tenha sido assinado pelo Governador Milton Soares Campos em 1948 sua inauguração somente ocorreu efetivamente no ano de 1962.

3 O IDORT apresentava o taylorismo como solução, propugnando o combate à desorganização administrativa das empresas, à utilização inadequada de matérias primas, de força de trabalho e de energia motriz, assim como a defesa da implantação de um controle eficiente dos custos. Segundo essa doutrina, a redução dos custos permitiria a elevação da produtividade e, em consequência, o aumento dos salários pagos aos trabalhadores o que desincentivaria os movimentos reivindicatórios. (CUNHA, 2000, p. 25).

${ }^{4}$ Segundo Soares (1995) desde os anos de 1930, Uberlândia foi denominada pela elite econômica de "Cidade Jardim", em função do controle das lideranças locais em prol da limpeza das ruas, avenidas, casas e principalmente pela manutenção da beleza das suas praças e jardins. Ao tratar esta mesma questão Rodrigues (1989) salienta que além de "Cidade Jardim" Uberlândia também ganhou outras denominações como "Metrópole do interior", "Capital do Brasil Central", "Meca Econômica, outra Nova York em pleno sertão do Brasil" dentre outros.

${ }^{5}$ Ver dissertação de Silva (2000) intitulada "Flores do Mal" na Cidade Jardim: comunismo e anticomunismo em Uberlândia.

${ }^{6}$ Rodrigues (1989) considerou as décadas de 1920 a 1960 as mais ricas no que se refere ao processo de organização e reivindicações trabalhistas em Uberlândia. $\mathrm{O}$ operariado uberlandense se fez presente nas diversas associações por ele criadas, nos sindicatos, círculos operários e partidos políticos.

${ }^{7} \mathrm{Em}$ relação ao fenômeno da violência na cidade é interessante atentar que essa questão geralmente estava associada a pessoas oriundas de outras cidades e que foram atraídas para Uberlândia em virtude de sua riqueza. (SOUZA JÚNIOR, 2007, p. 170).

${ }^{8}$ Guimarães (2010), ao realizar uma análise do contexto político e econômico nacional e seus impactos na região do Triângulo Mineiro nos anos 1950, lembra que essa década no Brasil foi marcada por uma ascendência inflacionária e o ano de 1959 especialmente foi um ano de dificuldades financeiras para a economia brasileira, agravadas com a moratória do Fundo Monetário Internacional (FMI).

Recebido: Outubro-2012

Aprovado: Fevereiro-2013 